\title{
Atividades administrativas e produção científica dos docentes: reflexos em Programas Brasileiros de Pós- Graduação em Física.
}

\section{Anna Elizabeth Galvão Coutinho Correia}

Professora do Departamento de Ciência da Informação da UFPE. Doutora em Ciências da Informação pela UFMG

\section{Lídia Alvarenga}

Professora do Departamento de Organização e Tratamento da Informação da ECI da UFMG.Doutora em Educação pela UFMG

Joana Coeli Ribeiro Garcia

Professora do Departamento de Ciência da
Informação da UFPB.Doutora em Ciência da
Informação pela UFRJ / IBICT

http://dx.org/10.1590/1981-5344/1824

Objetiva diagnosticar fatores intervenientes na produção científica, decorrentes da execução sistemática de atividades acadêmicas e administrativas, por parte dos docentes dos programas de pós-graduação na área da Física das Universidades Federais de Minas Gerais, Pernambuco e Rio de Janeiro, no período de 2007 a 2009. Utiliza a triangulação metodológica por contemplar a flexibilização dos métodos de natureza quantitativa (bibliometria e cientometria), qualitativa (análise de conteúdo). Constata necessidade de se incluir e pontuar, na avaliação trienal da Coordenação de Aperfeiçoamento de Pessoal de Nível Superior (CAPES), atividades administrativas e de extensão. Os resultados da pesquisa foram agrupados por docentes que exerceram atividades administrativas no Grupo 5 e os que não exerceram, verificando como se comportam em relação aos demais grupos. Assim, observa-se que no geral as atividades administrativas não influenciam as atividades acadêmicas para os Grupos 1 (atividades acadêmicas) e 2 (produção científica). No Grupo 3 (extensão) em que os docentes, em sua maioria exercem atividades administrativas de 
forma moderada, evidencia-se aumento da produção científica. Da comparação nesse extrato e período, conclui-se, de modo geral, que o fato dos docentes exercerem atividades administrativas não influencia a diminuição quantitativa das atividades acadêmicas, extensão e da produção científica.

Palavras-Chaves: Produção Científica; Atividades Administrativas; Atividades de Atividades acadêmicas; Atividades de Extensão; Programa de Pós-Graduação em Física.

\section{Administrative activities versus academic production of professors: reflections on graduate programs in physics.}

It aims to diagnose factors involved in the scientific production resulting from the systematic execution of academic and administrative activities, from professors of the graduate programs of Physics from Federal University of Minas Gerais, Pernambuco and Rio de Janeiro, in the period 2007-2009. It uses methodological triangulation to contemplate the quantitative (bibliometrics and scientometrics), qualitative (content analysis) and interpretive (content analysis) methods. There is a need to include and score in assessment triennial of the Coordination for the Improvement of Higher Level Personnel (CAPES), administrative and extension activities. The survey results were grouped by professors who executed administrative activities in Group 5, and those who did not execute, checking how they behave in relation to other groups. Thus, it is observed that the administrative activities do not influence the academic activities for Groups 1 (academic activities) and 2 (scientific). The Group 3 (extension) where professors mostly executing administrative activities in a moderate way, there was an increased in scientific production. The comparison in this period and extract, it appears, in general, that the administrative activities do not influence in the decrease in the amount of academic, extension and scientific production. 
Key-words: Scientific Production; Administrative Activities; Academic Activities; Extension; Graduate Program in Physics.

Recebido em04.06.2013 Aceito em 11.08.2014

\section{Introdução}

$\mathrm{Na}$ avaliação da ciência convive-se com instrumentos de avaliação que pontuam as atividades de docentes envolvidos com a Pós-Graduação. Governos de vários países. Seja do Brasil, Estados Unidos da América, Europa ou da Ásia adotaram o modelo, há algumas décadas; os cientistas passam a concorrer entre si em função de uma produtividade que, na maioria das vezes, torna-se mais quantitativa que qualitativa, para atender aos indicadores como elementos de avaliação da produção científica.

O desempenho e a consequente pontuação de pesquisadores estão associados à produtividade, ou seja, a quantidade de trabalho sendo vista para "[...] identificar quem trabalhava e quem não trabalhava, melhor dizendo quem produzia e quem não produzia"; essa visão da avaliação por desempenho possuía "um artifício punitivo e controlador da produção [...]." (BARBOSA, 1996, p. 61).

Ao se tratar de desempenho em instituições de ensino superior, entende-se que há envolvimento do docente em atividades administrativas, acadêmicas, de pesquisa e extensão No que se refere às atividades administrativas, evidencia-se que o professor se envolve com a burocracia instituída na administração seja em funções de direção, chefia, coordenação, ou comissões, atividades que demandam tempo em sua execução. No aspecto acadêmico o envolvimento é quanto às aulas, orientações de graduação e pós-graduação.

Nas atividades de pesquisa, o processo de produção científica é visto sob duas óticas: a primeira é a da prestação de contas do docente para com a sociedade que financia a pesquisa; e a segunda é entendida como um ciclo de desenvolvimento e produção de conhecimento científico que deve resultar em publicações (formais e informais). Assim, ao realizar pesquisa e comunicar seus resultados, os pesquisadores estão exercendo atividades essenciais para a disseminação do conhecimento.

Com base no exposto, a proposta deste estudo é diagnosticar fatores intervenientes na produção científica, decorrentes da execução sistemática de atividades acadêmicas e administrativas, por docentes dos programas de pós-graduação na área da Física das Universidades Federais de Minas Gerais, Pernambuco e Rio de Janeiro, no período de 2007 a 2009.

Este estudo é um extrato de pesquisa mais ampla de Correia (2012). Tal extrato poderá oferecer subsídios para a discussão, no âmbito da Ciência da Informação, sobre o exercício de atividades acadêmicas 
administrativas desempenhadas por docentes e as possíveis interferências na produção do conhecimento perante a execução de tais atividades.

Da mesma forma, pretendeu-se contribuir para a Ciência da Informação, no que diz respeito ao uso de indicadores métricos relacionados à produção científica, tendo como objeto de estudo a área da Física, em especial alguns de seus programas de pós-graduação com reconhecimento internacional.

\section{Procedimentos Metodológicos}

O estudo utilizou a triangulação metodológica por contemplar a flexibilização dos métodos de natureza quantitativa (bibliometria e cientometria), qualitativa (análise de conteúdo). Foram utilizadas três fontes: docentes (Coordenadores e representantes da área da Física no Sistema Nacional de Planejamento e Avaliação da Capes, além dos docentes que compõem dos referidos Programas); documentos que regulam os programas e estimulam a produção científica (Documento de área 2009, Relatório de Avaliação 2007-2009, Manual da Pós-Graduação, e regulamentos da Pós-Graduação); assim como uma análise da produção científica dos docentes entrevistados. Tais fontes possibilitaram identificar as interferências das atividades acadêmicas administrativas, na produção científica dos 156 docentes efetivos dos cursos de pósgraduação da área de Física das universidades: Federal de Minas Gerais (UFMG), com 54 docentes, 363 artigos; Federal de Pernambuco (UFPE), com 30 docentes, 224 artigos; e Federal do Rio de Janeiro (UFRJ): 69 docentes, 419 artigos, no período de 2007 a 2009; delimitou-se esse período por ser o de avaliação trienal da Capes.

Os dados das atividades acadêmicas administrativas e da produção científica foram coletados no período de 14 a 24 de março de 2010, recolhidos dos Currículos Lattes dos docentes, coordenadores e representantes da área da Física, tais como: atividades de ensino; produção científica, técnica, artística e cultural; atividades de extensão. Para extração das atividades constantes dos currículos, utilizou-se a ferramenta Scriptlattes, enquanto que para o tratamento bibliométrico utilizou-se o DataView. A ferramenta Scriptlattes agrupa e exclui a produção científica duplicada, enquanto o DataView cria diferentes visões dos dados armazenados em um DataTable, permitindo diversos critérios para ordenação e filtragem de dados, viabilizando a análise das questões referentes aos autores individualmente, a exemplo do número de publicações.

Para o estabelecimento da pontuação das atividades acadêmicas e administrativas buscou-se, nas instituições pesquisadas, normas que se adequassem às necessidades deste trabalho. Identificou-se que a UFMG e UFRJ não disponibilizam em suas normas as atividades de forma detalhada, optando-se pela UFPE, que apresentou as referidas atividades detalhadamente. 
Desse modo, utilizou-se a Resolução no 4/2008 - Conselho Universitário, que "Estabelece normas para a progressão horizontal e vertical para as classes de Professor Auxiliar, Assistente, Adjunto e Associado." (UNIVERSIDADE... 2008, p. 6). Para efetivação dos cálculos com as respectivas pontuações e pesos de cada grupo, utilizou-se o sistema adotado no Centro de Tecnologia e Geociências (CTG) da referida instituição, sistema elaborado no programa Excel que, ao ser preenchido, resulta em cálculo com os respectivos pesos.

Para adequação a este trabalho, considera-se apenas a pontuação dos grupos: Grupo 1 - Atividade Acadêmica (atividades de ensino, orientação de iniciação científica, pós-graduação, participação em bancas, etc); Grupo 2 - Produção científica, técnica, artística e cultural (Bolsista de produtividade, produção científica, produção artística, técnica, arbitragem de artigos técnicos científicos, prêmios, patentes, etc) ; Grupo 3 - Extensão (coordenação de programas, projetos, cursos de extensão aprovados institucionalmente, coordenação de eventos, etc); e Grupo 5 Atividade de administração (cargos de reitor, chefe de departamento, coordenação de curso de graduação e pós-graduação, participação em comissões, etc). O Grupo 4 - Formação e capacitação foi desconsiderado por não fazer parte do contexto analisado e também por não apresentar representatividade dentro da amostra.

Após a determinação da pontuação dos docentes dentro de cada grupo, utilizou-se o programa Excel para tabulação e hierarquização dos valores do menor para o maior, para análise e interpretação.

Assim, foram identificados, tanto os docentes que exerceram atividades do Grupo 5 (atividades administrativas), como os que não exerceram, comparando-as com as outras variáveis:

a) Grupo 5 (atividades administrativas), separados entre os conjuntos dos que exerceram e os que não exerceram atividades do referido grupo, relacionando com as atividades dos Grupos 1 (atividades acadêmicas) e 2 (produção científica), e

b) Grupo 5 (atividades administrativas) também separados entre os conjuntos dos que exerceram e os que não exerceram atividades do referido grupo, relacionando com as atividades dos Grupos 2 (produção científica) e 3 (extensão). O que possibilitou identificar a interferência entre as variáveis.

De posse dos dados, foram elaborados roteiros de entrevistas com a finalidade de saber a opinião dos docentes, coordenadores e representantes de área de Física na Capes sobre a política de avaliação. 0 uso desse instrumento se justifica por aproximar o entrevistador do entrevistado, possibilitando registrar suas impressões relativas ao sistema avaliativo, enquadrá-lo nas categorias de análise, bem como dirimir e/ou compreender controvérsias porventura existentes.

Assim, foram elaborados três roteiros distintos e aplicados pessoalmente, no período de 26 de outubro a 26 de novembro de 2010, o que totalizou 103 docentes entrevistados (UFMG $=43$, UFPE $=17$ e UFRJ $=43$ ). 
Tanto nos documentos normatizadores como nas entrevistas, utilizou-se a técnica de análise de conteúdo proposta por Bardin (2008), explorando o que foi identificado igualmente junto aos atores envolvidos e nos referidos documentos.

As entrevistas foram transcritas integralmente sendo passadas depois para a forma da língua culta, dando melhor entendimento às ideias explicitadas pelos atores. Assim, utilizou-se o modelo temático-categorial de análise, por ser uma análise de conteúdo que implica operações de desmembramento de texto, seccionando partes que correspondam às temáticas. Dessa forma, tornou-se possível interpretar, nos documentos normatizadores e resultados das entrevistas dos pesquisadores envolvidos, discursos que, aparentemente simbólicos e polissêmicos, escondem um sentido que convém desvendar (BARDIN, 2008, p.16).

\section{Análise dos Dados}

Os dados são explorados levando-se em consideração os docentes que exerceram e os que não exerceram atividades do Grupo 5 (atividades administrativas), verificando as interferências na produção científica, nas atividades acadêmicas e extensão, dos docentes dos programas de pósgraduação em Física da UFMG, UFPE e UFRJ, no período de 2007, 2008 e 2009. Inicialmente os documentos da Capes e dos três Programas de PósGraduação estudados são abordados sob a ótica das atividades administrativas, verificando os pontos que exigem do docente o exercício da administração. Em seguida são expostas as sugestões dos docentes, obtidas através das entrevistas, assim como a inclusão de algumas atividades como itens avaliativos.

Posteriormente os dados das atividades exercidas pelos docentes dos três programas são apresentados, indicando as respectivas pontuações. Na continuidade os resultados são separados por grupos de docentes que exerceram atividades do Grupo 5 (atividades administrativas) e os que não exerceram. Inicialmente são comparados com os dados do Grupo 1 (atividades acadêmicas), e do Grupo 2 (produção científica); em sequência com o Grupo 2 (produção científica) e o Grupo 3 (atividades de extensão), também apreciando o comportamento em relação ao Grupo 5 (atividades administrativas). Vale salientar que, nos dados analisados, não foram considerados fatores externos que podem interferir na produção científica, como: físicos, psicológicos, e estruturais. Fez-se um estudo comparativo entre os dados quantitativos quando do exercício ou não de atividades administrativas.

Atividades administrativas são essenciais para o funcionamento de qualquer instituição. Em se tratando de instituições de ensino superior, tais atividades são desenvolvidas pelos docentes que exercem várias funções, desempenhando, além delas, o cargo de docente, todas indispensáveis aos três pilares que regem a universidade: ensino, pesquisa e extensão. Assim, os docentes assumem cargos de chefia, coordenação, presidência, ou como membros de comissões e também as 
orientações de alunos de graduação (trabalhos de conclusão de curso e de iniciação científica) ou de pós-graduação (mestrado e doutorado), além de exercerem as atividades de docente, na graduação e na pós-graduação.

Ao analisar os documentos normatizadores da Capes identificou-se que manter a infraestrutura adequada é condição sine qua non para a avaliação do programa, embora não se atribua peso, a não ser quando necessário, para o estabelecimento da nota final. Dessa forma, no documento de área Astronomia e Física (COORDENAÇÃO... 2009, p.6, grifo nosso) o quesito 1 , proposta do programa, estabelece que:

Por decisão do CTC-ES, não há atribuição de peso a este quesito. Os itens deste quesito são avaliados pelos mesmos padrões dos demais e há uma atribuição de conceito qualitativo para cada item. Este quesito passará a ser considerado como 'trava' para a definição do conceito final.

A infraestrutura abrange tudo o que diz respeito ao ambiente, salas de aula, laboratórios e equipamentos que apoiam tanto o ensino como a pesquisa. Eles estão especificados no referido documento, item 1.3, infraestrutura para ensino, pesquisa e extensão, determinando que:

Espera-se que a infraestrutura inclua salas de aula adequadas, recursos computacionais adequados para ensino e pesquisa, apoio aos laboratórios de pesquisa teóricos e experimentais adequados, salas para estudantes e professores permanentes e visitantes adequadas. (COORDENAÇÃO... 2009, p. 6)

Para se manter uma infraestrutura adequada é necessária uma boa administração que proveja prédios, equipamentos e pessoal qualificado que funcionem de forma satisfatória. Nesse sentido acredita-se que se deva gerenciar salas de aula e laboratórios, que atendam às necessidades de pesquisa, teórica ou experimental, tanto do corpo docente efetivo, quanto para professores visitantes. Salienta-se ainda a administração do pessoal técnico e docentes, na execução de suas funções a fim de se verificar se estão cumprindo o que determinam os documentos normatizadores institucionais do programa de pós-graduação e da Capes.

Esse item consta do relatório da avaliação do último trimestre, analisado de acordo com o seguinte critério:

A avaliação deste item foi qualitativa, a partir da análise, por cada consultor, da proposta do programa e a descrição da infraestrutura. Foi verificado se houve visita ao programa e a descrição da infraestrutura por parte dos consultores que o visitaram. Foi avaliado como MB o programa que atendeu aos critérios descritos 
no documento de área, ou $B, R, F$ em função do grau de não atendimento. (COORDENAÇÃO..., 2011, p. 4)

Dessa forma, a avaliação foi feita através de visitas verificando in loco como a infraestrutura se encontrava e se atendia às necessidades do programa. Com isso, os docentes que exercem a função de coordenação devem ter o cuidado de fiscalizar a infraestrutura para que a mesma atenda às necessidades dos docentes e discentes do programa, tendo em vista que este item poderá ser atribuído e considerado na nota final da avaliação.

Voltando ao documento de área, item 2.2, adequação e dedicação dos docentes permanentes em relação às atividades de pesquisa e de formação, o programa deve oferecer disciplinas específicas e eletivas diversificadas e estabelece:

Caso o programa não ofereça disciplinas básicas de Teoria Quântica, Eletrodinâmica Clássica e Mecânica Estatística (ou equivalentes) para os cursos de Física, poderá ser penalizado, assim como os programas de Astronomia que não oferecerem disciplinas básicas para sua área.

Observar-se-á também a oferta diversificada e sistemática de disciplinas eletivas, tópicas, seminários, etc., e sua consistência e coerência com a proposta do programa e suas linhas de pesquisa. Será também avaliada a distribuição de atividades didáticas na PG entre os docentes do quadro permanente, valorizando uma maior participação do quadro como um todo (COORDENAÇÃO... 2009, p.7, grifo nosso)

Fica evidenciado que a oferta de disciplinas específicas, eletivas variadas e a distribuição de atividades didáticas são importantes no processo avaliativo, podendo-se inclusive penalizar o programa caso não sejam ofertadas. $O$ referido item tem como objetivo estimular aos docentes a elaborarem conteúdos novos às disciplinas para 0 aprimoramento do aprendizado, o que acarreta desprendimento de tempo para exercer também tal atividade.

Já o item 2.4 do referido documento estabelece a contribuição dos docentes para atividades de ensino ou de pesquisa na graduação, identificando tanto a repercussão que pode ter na formação de futuros ingressantes na pós-graduação, quanto na formação de profissionais mais capacitados no plano da graduação. Este item tem validade quando o programa for ligado a curso de graduação; caso contrário, o peso é redistribuído proporcionalmente entre os demais itens do quesito, que assim estabelece: 
no caso de programas associados a IES com atividades de graduação, será avaliada a participação em ensino de graduação de docentes do quadro permanente da PG, bem como a existência de um vigoroso programa de Iniciação Científica, mesmo para os programas que não estejam envolvidos com atividades didáticas de graduação (COORDENAÇÃO... 2009, p. 8, grifo nosso)

Exige-se que o docente estimule os alunos da graduação, a se tornarem alunos da pós-graduação, por meio de participação em pesquisas e de programas de iniciação científica. Tal fato é constatado quando o docente UFPE, Docente 5 afirma que a orientação é importante, que todo docente deve orientar e ressalta:

Nós não trabalhamos com uma fábrica de alunos. Nós trabalhamos, essencialmente, da mesma maneira que se trabalhava na Idade Média. Se você não tem um contato direto com um aluno, e você não influencia diretamente na formação dele, você não está transmitindo conhecimento, fica muito mais difícil produzir conhecimento (UFPE Docente 5).

Essa prática é necessária principalmente para os alunos da graduação que não têm experiência na atividade de pesquisa, exigindo que o docente dedique mais tempo para orientá-los. Quanto à orientação de alunos na pós-graduação, os documentos normatizadores das universidades estudadas mencionam que o docente, para se manter na pós-graduação deve ter orientações, seja de mestrado ou doutorado, quando for o caso (UNIVERSIDADE..., 2009; UNIVERSIDADE..., 2010; UNIVERSIDADE..., 2011).

Em relação à distribuição de orientação, o documento de área (COORDENAÇÃO... 2009, p. 9), item 3.2, distribuição das orientações das teses e dissertações defendidas no período de avaliação em relação aos docentes do programa, verifica o tempo médio de titulação, bolsistas titulados, e estabelece que:

serão verificados os tempos médios de titulação do mestrado, do doutorado e do doutorado direto, quando comparados com a média nacional. Será também considerado como indicador de eficiência 0 percentual de bolsistas titulados (COORDENAÇÃO... 2009, p.9)

No relatório do último triênio este item foi avaliado, de acordo com o seguinte critério: 
Foram analisados os tempos médios de titulação para o mestrado e doutorado no triênio, obtendo-se os valores 24,5 meses e 51 meses, respectivamente. Os programas foram analisados com base nestes valores médios, usando os seguintes critérios:

MB para programas com tempo de titulação abaixo da média ou até $10 \%$ acima da média.

$B, R$ ou $F B, R, F$ em função do grau de não atendimento ao critério (COORDENAÇÃO... 2011, p. 6).

É constatado que o coordenador do programa de pós-graduação, além de exercer atividades de docência, de pesquisa e administrativas, deve ter cuidado para não deixar que os alunos ultrapassem o prazo estabelecido, exercendo controle dos corpos docente e discente. Ressaltase que fazer ciência requer tempo para incorporar teorias e gerar novos conhecimentos consistentes que, por sua vez, geram outras teorias e conhecimentos. Assim os experimentos são realizados, observados e, dependendo, podem ser apresentados à comunidade científica ou simplesmente rejeitados, por necessitarem de amadurecimento e consistência. Ao se estabelecer prazos curtos, correm-se riscos de lançar à comunidade científica resultados de pesquisas inconsistentes que podem gerar repercussão negativa.

Enfatiza-se também que os programas de pós-graduação em Física da UFPE e UFMG, exigem para defesa de tese a publicação ou aceite de pelo menos um artigo em revistas indexadas como explicitado nos documentos: Manual da Pós-Graduação da UFPE, publicado em 2011, e o Regulamento do Programa de Pós-Graduação da UFMG, 2010, em seus artigos 43 da UFPE e 63 da UFMG, que destacam:

Art. 43 A Dissertação e a Tese deverão constituir trabalho final de pesquisa com caráter individual e inédito.

$\S 10$ A Tese deverá refletir a importância de sua contribuição para a área de conhecimento e a sua originalidade. A originalidade deve ser comprovada pela publicação ou aceitação de pelo menos um artigo em revista indexada 30 (trinta) dias antes da data da defesa da Tese. (UNIVERSIDADE..., 2011, p. 26, grifo nosso)

Art. 65- Para obter o grau de Doutor, o candidato deverá satisfazer pelo menos as seguintes exigências, no prazo mínimo de vinte e quatro (24) meses e máximo de sessenta (60) meses, contados a partir da data da matrícula inicial: [...]

c) apresentar pelo menos um (1) trabalho aceito para publicação ou publicado em periódico indexado, trabalho 
este relacionado à tese do estudante. Em caso de múltiplos autores, deve, necessariamente, ficar clara a contribuição do estudante. (UNIVERSIDADE..., 2010, p. 12, grifo nosso)

Ou seja, o pós-graduando é estimulado a publicar os resultados de suas pesquisas, mesmo que precocemente, atendendo o que rege nos documentos normatizadores, reforçando o que Reinach afirma em seu artigo "Darwin e a prática da 'Salami Science"" publicado no Estado de S. Paulo (27 de abril de 2013), que " 'Salami Science, espero que não chegue aqui'. Mas a praga se espalhou pelo mundo e agora assola a comunidade científica brasileira [...] E a cada dia ficamos mais longe de ter cientistas que possam ser descritos em uma única frase: Ele descobriu...". (REINACH, 2013, p.1). Isso ocorre devido à pressão que o pesquisador, ou pós-graduando sofre, pelas exigências contidas nos documentos normatizados da CAPES e das instituições citadas, induzindoos a publicar, ainda que os experimentos não apresentem resultados significativos.

Os coordenadores dos programas de pós-graduação, também devem ter o cuidado de controlar não apenas a produção docente, mas também a produção discente, fazendo cumprir as normas, e assim mantendo ou melhorando o nível do referido programa.

Como apresentado, a avaliação do programa é feita através do conjunto de atividades exercidas pelos docentes que, em alguns casos, exercem vários cargos administrativos e atividades que podem prejudicar o desenvolvimento da produção científica e, consequentemente, do programa. Assim, os docentes sugerem que algumas atividades sejam incorporadas ao processo avaliativo da CAPES por entenderem que são partes desse processo; em alguns casos, tais atividades trazem visibilidade ao programa, mas devem ser incluídas parcimoniosamente para não estimular a burocracia, como salientam os docentes:

[...] coordenações e chefias são atividades que alguém tem que exercer, quem exerce acaba se envolvendo, e diminuindo a produção científica. Teria que ser levado de alguma forma em conta (UFMG Docente 23);

[...] acho que é uma coisa importante que deve ter algum tipo de valorização, talvez certa valorização por parte da Capes sim. Não valorizar em excesso porque isso você pode transformar a pessoa em um burocrata (UFMG Docente 34).

Os docentes entendem que são atividades essenciais para o funcionamento do programa e que sejam consideradas no processo de avaliação. Dessa forma, sugerem que algumas atividades sejam incorporadas na avaliação, como, por exemplo:

organização de eventos internacionais - 42,3\% indicaram que se trata de atividade importante, trabalhosa, e que proporciona visibilidade para o programa. Dessa forma merecia atenção, e ser avaliada. 
criação de nova linha de pesquisa - 37,2\% indicaram esta como uma forma de estímulo à criatividade, fazendo com que o docente saia do "feijão com arroz" e corra mais riscos. Para isso necessita de tempo e amadurecimento, para que sejam produzidos conhecimentos. Mas deve ter cautela quanto a esta atividade, para não serem criadas linhas em excesso.

coordenação / chefias - 30,1\% indicaram como necessário que estas atividades façam parte da avaliação, tendo em vista que são essenciais para manutenção e bom funcionamento do programa sem, no entanto, estimular demasiado para não criar meros burocratas. Alguns docentes afirmaram ainda que estas atividades deveriam ficar em mãos de administradores, deixando-os livres para atividades acadêmicas; porém, no processo de avaliação da Capes, o administrador deve participar, tendo em vista que ele é o executor das atividades avaliadas.

acompanhamento de professor visitante - $25,6 \%$ indicaram como importante no processo avaliativo, por tratar-se da visibilidade do programa, devendo-se, no entanto, verificar atentamente se se trata realmente de professor visitante que veio contribuir para o amadurecimento do conhecimento dos que fazem o programa, e consequentemente participando do aumento da produção científica.

As atividades mencionadas acima são exercidas pelos docentes, dentre outras mais burocráticas. Tais atividades são essenciais para 0 funcionamento adequado da instituição como um todo, e podem interferir na produção científica. Elas foram levantadas e extraídas do Currículo Lattes dos 156 docentes dos referidos programas de pós-graduação. Para análise dos dados e comparação entre as variáveis ensino, pesquisa, extensão e atividades administrativas, foi utilizado o parâmetro apresentado nos procedimentos metodológicos.

Analisando as atribuições exercidas e pontuando por grupo, tem-se: - Grupo 1 representa atividades acadêmicas; o Grupo 2, produção científica, técnica, artística e cultural; o Grupo 3, atividades de extensão; o Grupo 4, atividades de formação e capacitação acadêmica; e o Grupo 5, atividades de administração.

Evidenciou-se que os Grupos 1 (atividades acadêmicas), 2 (produção científica, técnica, artística e cultural) e 3 (extensão) possuem mais representatividade, com $27 \%, 47 \%$ e $25 \%$, respectivamente, já o Grupo 5 (atividades administrativas) possui apenas 1\% representando concentração na execução das atividades administrativas. Ressalta-se ainda que no Grupo 1 (atividades acadêmicas), em sua maioria, constam orientações; o Grupo 2 (produção científica, técnica, artística e cultural) é composto por: pesquisadores que têm bolsas produtividade de pesquisa, arbitragem em artigos científicos e produção científica, contabilizando apenas os artigos em periódicos; no Grupo 3 (extensão) estão atividades de extensão representadas pelos projetos selecionados em editais, e por organização de eventos internacionais, nacionais e locais; e no Grupo 5 (atividades administrativas) estão atividades exercidas, como direções, chefias, comissões, etc. Deve-se explicitar que, por não fazer parte do 
contexto da pesquisa o Grupo 4 não está contemplado, como dito na metodologia.

A seguir são apresentados os dados relativos aos docentes que não exercem atividades do Grupo 5 (atividades administrativas), verificando o comportamento em relação aos Grupos 1 (atividades acadêmicas) e 2 (produção científica, técnica, artística e cultural), representados no Gráfico 1. Posteriormente os que exercem atividades do Grupo 5 (atividades administrativas), também observando como se comportam quanto às atividades do Grupo 1 (atividades acadêmicas) e 2 (produção científica, técnica, artística e cultural), representados no Gráfico 2. A seguir são verificados, na mesma sistemática, em relação às atividades exercidas nos Grupos 2 e 3, que estão representados no Gráfico 3 e 4.

O Gráfico 1 apresenta as médias dos dois grupos (Grupo 1 e 2), seguidas pelos números de pontos obtidos nos referidos grupos, e pelo limite mínimo desejável - que é a pontuação mínima para obter a progressão. Para maior consistência na análise dos dados foram calculadas as médias, o desvio padrão e o coeficiente de variação (CV).

O Grupo 1 (atividades acadêmicas) apresenta uma média de 8,97; e - Grupo 2 (produção científica, técnica, artística e cultural), de 8,29. Calculando o desvio padrão dos Grupos, temos no Grupo 1 (atividades acadêmicas) o valor de 0,88, e no Grupo 2 (produção científica, técnica, artística e cultural) de 1,40. O CV do Grupo 1 (atividades acadêmicas) é de $9,8 \%$ e o do Grupo 2 (produção científica, técnica, artística e cultural)é de $17 \%$.

Observa-se que dos 80 docentes, 33 se encontram abaixo da média no Grupo 1 (atividades acadêmicas) e, destes, nove se mantêm no limite mínimo desejável. Vale ressaltar que o referido grupo é composto basicamente por orientações, constatando-se que os nove docentes apresentaram baixo número de alunos orientandos.

Gráfico 1 - Grupos 1 e 2 - Docentes Sem Atividades Administrativas (UFMG, UFPE, UFRJ)

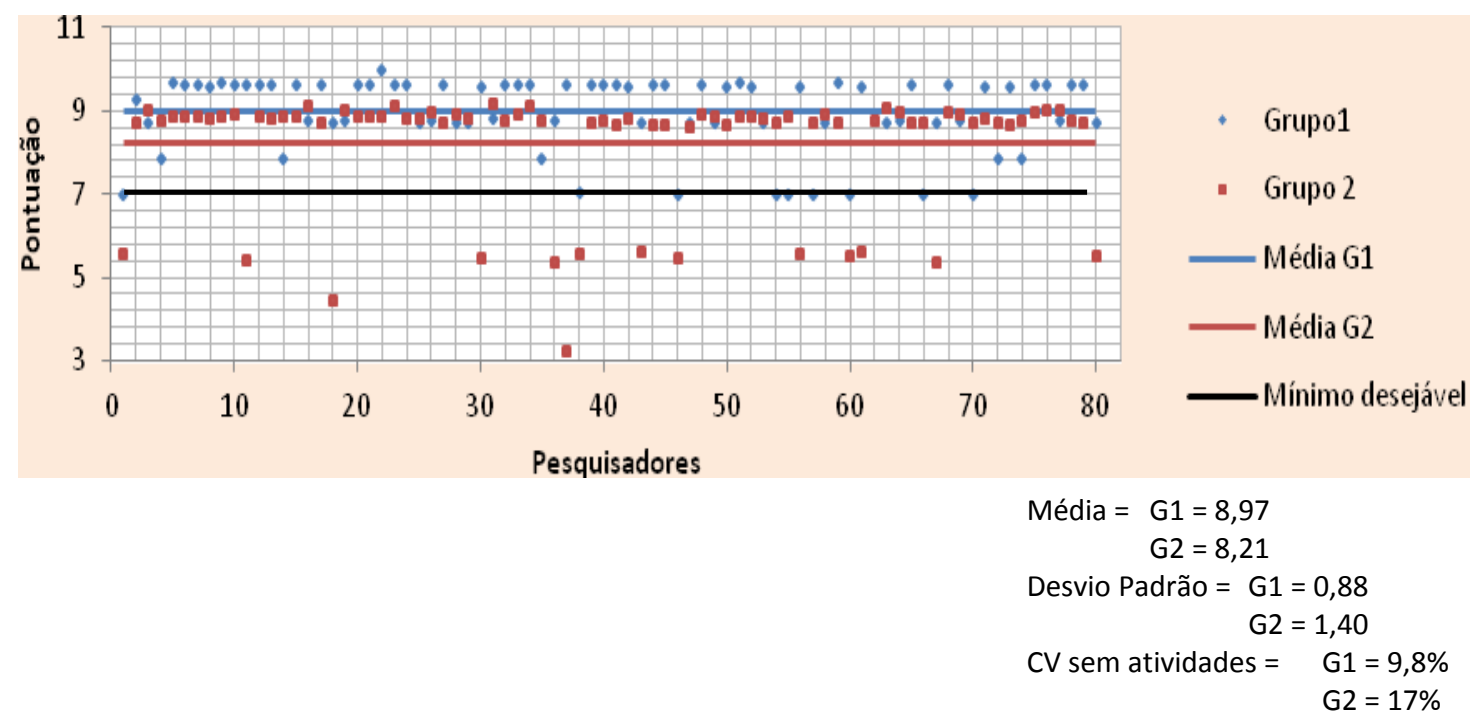

Fonte: Dados da pesquisa 
O Grupo 1 (atividades acadêmicas) apresenta baixa dispersão; já o Grupo 2 (produção científica, técnica, artística e cultural) possui somente um docente com média de 3,4, razão pela qual a dispersão do grupo ficou superior. O CV do Grupo 1 (atividades acadêmicas) é considerado baixo, indicando dados homogêneos, o que significa distribuição das orientações entre os docentes. Já no Grupo 2 (produção científica, técnica, artística e cultural), o CV é considerado médio, apresentando leve heterogeneidade, indicando que existe leve concentração da produção científica.

Evidencia-se que não exercer atividades administrativas, não interferiu para 0 aumento das atividades do Grupo 1 (atividade acadêmica) uma vez que 33 dos docentes que não exerceram atividades do Grupo 5 (atividades administrativas) e se encontram abaixo da média. No que se refere às atividades do Grupo 2 (produção científica, técnica, artística e cultural), nove dos docentes se apresentam abaixo da média e do limite mínimo desejável, evidenciando que não exercer atividades do Grupo 5 (atividades administrativas) não fez com que aumentasse a produtividade desse pequeno grupo; já para os 71 dos docentes não exercer atividades do referido grupo, fez com que a produção ficasse acima da média e, consequentemente, do mínimo desejável; neste caso, pode-se constatar que houve interferência nas atividades.

O Gráfico 2 apresenta o comportamento dos docentes que exerceram atividades do Grupo 5 (atividades administrativas), e dos Grupos 1 (atividade acadêmica) e 2 (produção científica, técnica, artística e cultural). As médias dos referidos grupos são: Grupo 1 (atividade acadêmica) de 9,22, e o Grupo 2 (produção científica, técnica, artística e cultural) de 8,39. O desvio padrão dos grupos é de 0,76 e 1,13, respectivamente, e o CV do Grupo 1 (atividade acadêmica) é de $8,2 \%$ e o do Grupo 2 (produção científica, técnica, artística e cultural) é de 13,5\%.

Identifica-se que dos 71 docentes, 19 encontram-se abaixo da média no Grupo 1 (atividade acadêmica). Destes, quatro estão no limite desejável. O referido grupo apresenta baixa dispersão e baixo CV, representando distribuição homogênea entre os docentes das atividades do grupo.

No Grupo 2 (produção científica, técnica, artística e cultural), apenas nove docentes se mantiveram abaixo da média e do limite mínimo desejável. O referido grupo apresenta dispersão relativamente alta, em que os nove docentes possuem média muito inferior aos demais, o que significa que há concentração das atividades do grupo em alguns docentes. O CV deste grupo é considerado médio, indicando leve heterogeneidade, demonstrando que a distribuição não é igualitária. 
Gráfico 2 - Grupos 1 e 2 - Docentes Com Atividades Administrativas (UFMG, UFPE, UFRJ)

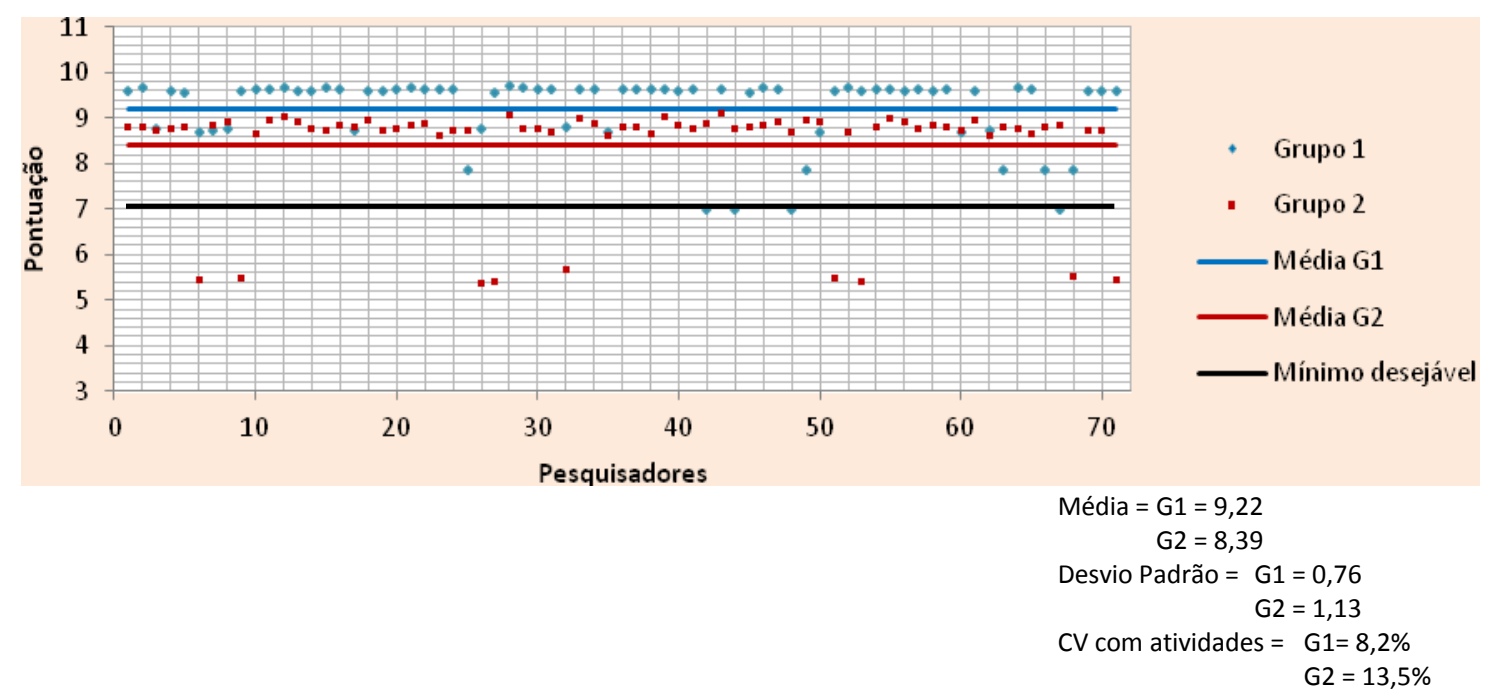

Fonte: Dados da pesquisa

Os dados evidenciam que, para 19 docentes que exerceram atividades do Grupo 5 (atividades administrativas) apresentou-se menor quantitativo nas atividades do Grupo 1 (atividades acadêmicas) por se encontrarem abaixo da média. Já para o Grupo 2 (produção científica, técnica, artística e cultural) mostrou-se uma diminuição mais acentuada, tendo em vista que nove docentes se mantiveram abaixo da média do Grupo e do mínimo desejável.

Observa-se também que, dos docentes que se encontram abaixo da média no Grupo 2 (produção científica, técnica, artística e cultural), quatro estão abaixo da média no Grupo 1 (atividades acadêmicas), evidenciando que, para este grupo de docentes o exercício de atividades administrativas interferiu no exercício dos dois grupos.

A seguir serão apresentados os pesquisadores que não exerceram (GRÁFICO 3) e os que exerceram (GRÁFICO 4) atividades do Grupo 5 (atividades administrativas) verificando como se comportam ao exercerem atividades dos Grupos 2 (produção científica, técnica, artística e cultural) e 3 (extensão).

Salienta-se que as atividades de extensão encontradas nos Currículos Lattes dos referidos docentes são projetos selecionados em editais, e organização de eventos, internacionais, nacionais ou regionais.

Do total de 99 docentes que exerceram as atividades do Grupo 3 (extensão), 49 não exerceram atividades do Grupo 5 (atividades administrativas); assim, encontrou-se para o Grupo 2 (produção científica, técnica, artística e cultural) a média de 8,46 e para o Grupo 3 (extensão) de 6,28. O desvio padrão é elevado em ambos os grupos, sendo encontrados 2,09 para o Grupo 2 (produção científica, técnica, artística e cultural), e 1,91 para o Grupo 3 (extensão). O cálculo do CV foi de 24,7\% e $30,4 \%$, respectivamente. 
A média do Grupo 3 (extensão) é inferior ao valor mínimo desejável, e 31 docentes encontram-se abaixo da média do grupo. Destes, cinco docentes posicionam-se abaixo da média no Grupo 2 (produção científica, técnica, artística e cultural), dos quais apenas um encontra-se acima da média no Grupo 3 (extensão).

Gráfico 3 - Grupos 2 e 3 - Docentes Sem Atividades Administrativas (UFMG, UFPE, UFRJ)

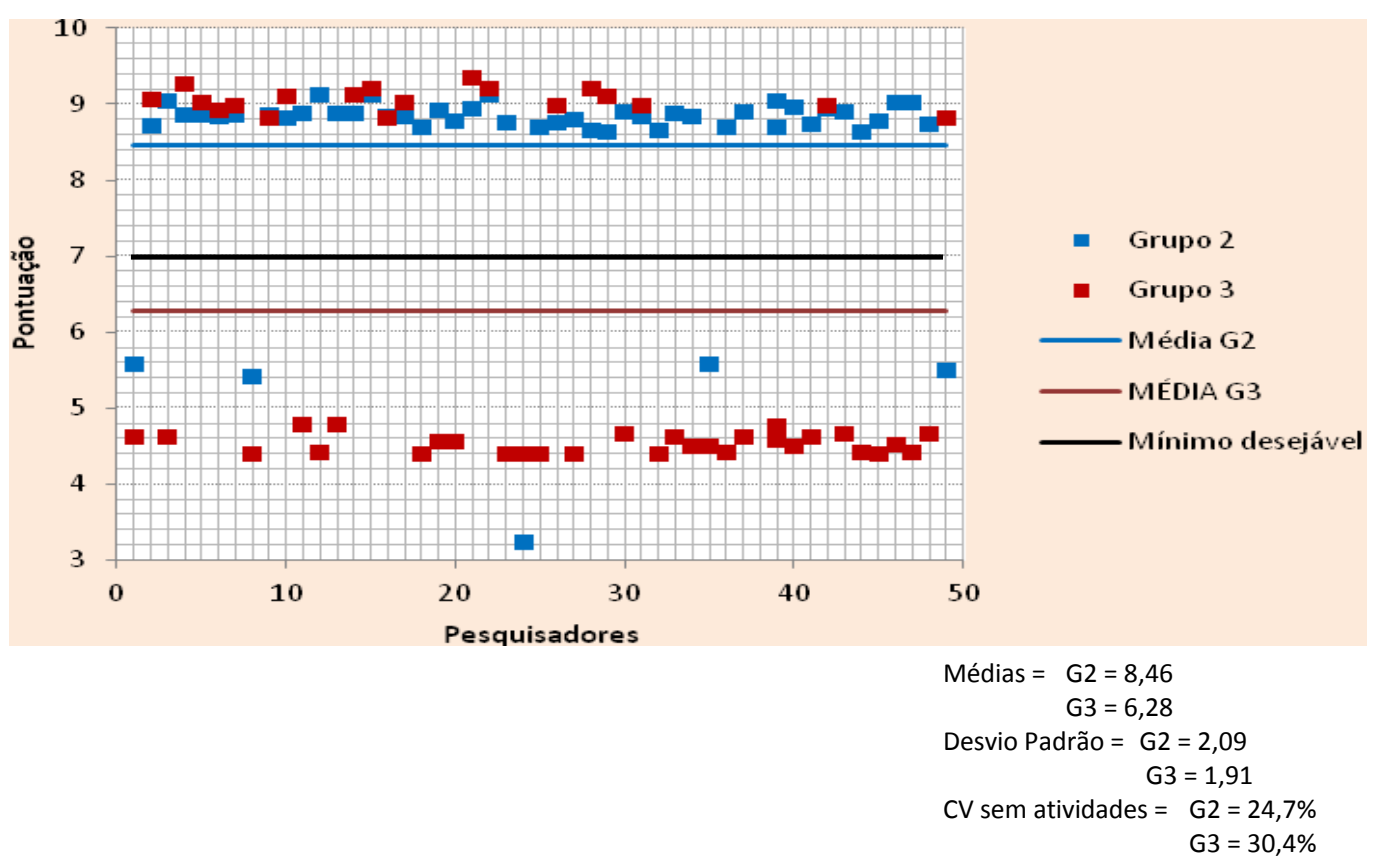

Fonte: Dados da pesquisa.

O desvio padrão dos grupos é alto, representando dispersão acentuada. O CV do Grupo 2 (produção científica, técnica, artística e cultural) é considerado alto, e o do Grupo 3 (extensão), muito alto, evidenciando em ambos os casos heterogeneidade entre as atividades de produção científica e de extensão. Salienta-se que, mesmo não exercendo atividades administrativas, a maioria dos docentes também não exerceu atividades de extensão, apesar de os docentes indicarem que essas atividades mereciam atenção por representarem visibilidade do programa, e deveriam ser incluídas na avaliação da CAPES.

Mesmo com a média do Grupo 3 inferior ao mínimo desejável, identifica-se que dos 49 docentes que exerceram tais atividades, 44 se apresentam acima da média no Grupo 2 (produção científica, técnica, artística e cultural), e cinco estão baixo da media e do limite desejável. Observa-se que apesar deste pequeno grupo não exercer atividades do Grupo 5 (atividades administrativas), desenvolvem poucas atividades de extensão, e não mantém a produção científica na média. No entanto, os outros 44 docentes se apresentam acima da média no Grupo 2 (produção científica, técnica, artística e cultural), o que leva a crer que foi facilitado o aumento da produção científica.

No Gráfico 4 estão os 50 docentes das instituições estudadas que exerceram atividades administrativas no período. Esses docentes 
apresentaram as seguintes médias: 8,57 para o Grupo 2 (produção científica, técnica, artística e cultural), e 6,92 para o Grupo 3 (extensão). O desvio padrão dos grupos é de 0,91 e 2,33, respectivamente. O CV do Grupo 2 é 10,6\%, e o do Grupo 3 (extensão), de 33,7\%.

Ressalta-se que a média do Grupo 3 (extensão) é inferior ao limite mínimo desejável, porém 26 docentes apresentam-se acima do referido limite e 24 se apresentam abaixo da média do grupo, e consequentemente do limite mínimo desejável. Observando o CV dos grupos, identifica-se que o Grupo 2 (produção científica, técnica, artística e cultural) possui CV médio, e o Grupo 3 (extensão), muito alto, representando heterogeneidade nos referidos grupos no exercício das atividades administrativas.

Gráfico 4 - Grupos 2 e 3 - Docentes Com Atividades Administrativas (UFMG, UFPE, UFRJ)

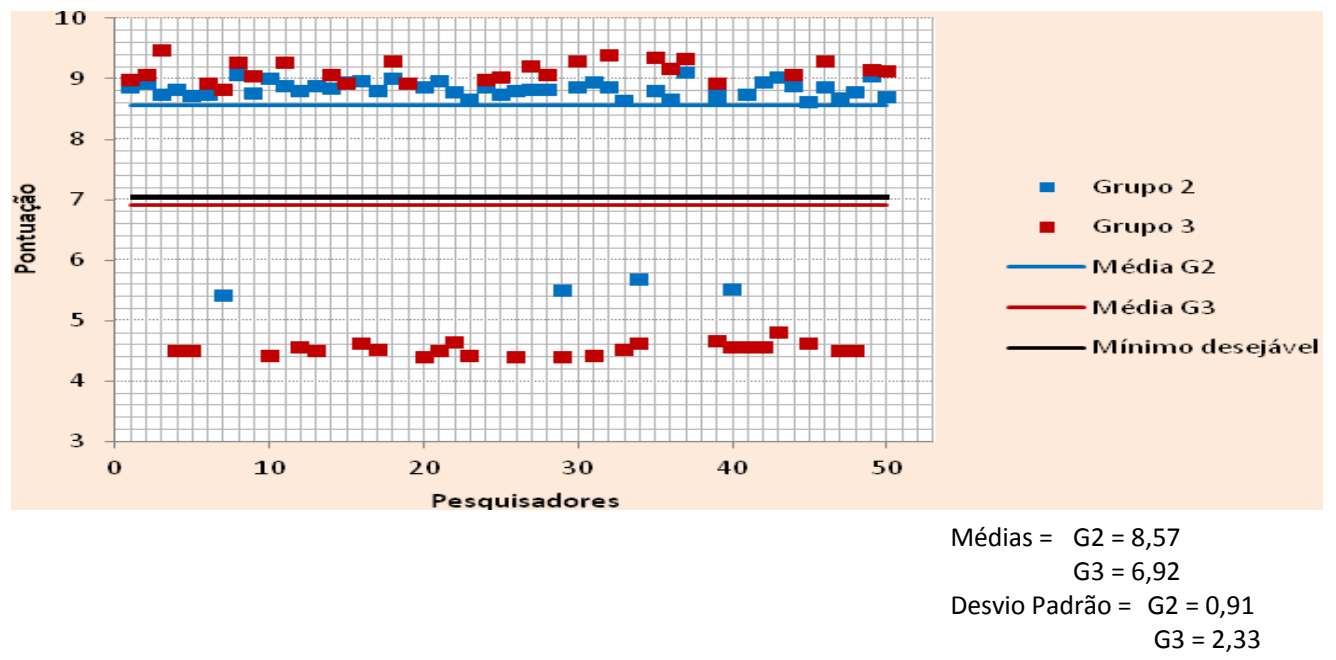

Fonte: Dados da pesquisa.

O CV dos que exercem e daqueles que não desempenham atividades do Grupo 5 (atividades administrativas) são semelhantes em ambos os grupos, ou seja, os grupos de docentes desenvolvem as atividades nos dois grupos de forma similar, no exercício ou não de atividades do Grupo 5 (atividades administrativas). Constata-se também que as atividades de extensão são pouco exercidas, representando concentração em alguns docentes.

Chama a atenção o fato de que quatro docentes mostram produção científica abaixo da média. Um encontra-se no Grupo 3 (extensão) acima da média, e três se apresentam abaixo do limite mínimo desejável. Para os três últimos, constata-se que exercer atividades do Grupo 5 (atividades administrativas) interferiu no desenvolvimento das atividades do Grupo 2 (produção científica, técnica, artística e cultural) e 3 (extensão).

\section{Considerações Finais}

Observa-se que as atividades administrativas estão citadas nos documentos normatizadores da Capes apresentando itens relacionados à 
avaliação que exigem dos docentes desempenhos administrativos, fazendo com que a infraestrutura dos programas atenda às necessidades acadêmicas.

Entende-se ainda, que o docente deve ser o elo entre a graduação e a pós-graduação, estimulando os alunos da graduação a participarem de pesquisa e de programa iniciação científica a se tornarem alunos da pósgraduação. No que se refere à orientação de alunos na pós-graduação, os documentos normatizadores dos programas de pós-graduação estudados citam que o docente, para manter-se na pós-graduação, deve ter orientações, seja de mestrado ou doutorado, quando for o caso. Além de verificar o tempo médio de titulação, verificando também o percentual de bolsistas titulados.

No que se refere às atividades exercidas os docentes sugeriram que algumas atividades fizessem parte da avaliação por serem essenciais e representarem a visibilidade que o programa tem ante a área. Tais como: organização de eventos internacionais; criação de nova linha de pesquisa; coordenação / chefias; acompanhamento de professor visitante. Ressalta que tais atividades são necessárias para o desempenho de um programa de pós-graduação e demandam tempo.

Quanto às atividades exercidas pelos docentes, constatou-se que os Grupos 1 (atividades acadêmicas), 2 (produção científica, técnica, artística e cultural) e 3 (extensão) apresentam percentuais elevados; já as atividades do Grupo 5 concentram-se em pequeno grupo de docentes atingindo apenas 1\%. O Grupo 2 (produção científica, técnica, artística e cultural) se destaca com um percentual de $47 \%$, salientando-se que este é formado pela produção científica, pelos bolsistas de produtividade, e por docentes que fazem parte do corpo de avaliadores de revistas científicas, evidenciando mais uma vez que o grupo é produtivo. Os Grupos 1 (atividades acadêmicas) e 3 (extensão) apresentam percentuais igualmente representativos, com $27 \%$ e $25 \%$, respectivamente. Vale questionar se está ocorrendo acúmulo de atividades, e se os docentes estão utilizando horas de lazer para dar conta de todas essas atividades, sobrecarregando-os. A sobrecarga de atividades exercidas pelos docentes tem causado fortes efeitos, e muitas vezes em prol da produção, eles sacrificam seu repouso, as férias e até mesmo o lazer, como mencionado por Rosa (2008).

No que se refere à interferência no exercício ou não de atividades do Grupo 5 (atividades administrativas), nos Grupos 1 (atividades acadêmicas) e 2 (produção científica, técnica, artística e cultural), observa-se que em geral estas não influenciam as atividades dos grupos. Constata-se, entretanto que existem dispersões que devem ser levadas em conta, através de estudos mais profundos, devendo ser verificado no Grupo 1 (atividades acadêmicas) se existem problemas no preenchimento do Lattes, ou se realmente não existe demanda suficiente de orientação em determinadas áreas da Física.

Assim, constata-se que os docentes exercem atividades administrativas e que, de modo geral, estas não influenciam na 
diminuição das outras atividades (atividades acadêmicas, pesquisa e extensão), nem mesmo da produção científica. Mas evidencia-se a existência de dispersões. Tais dispersões devem ser consideradas e analisadas posteriormente em estudos mais aprofundados, verificando ainda as datas de atualizações do Currículo Lattes e se existem problemas no seu preenchimento.

Finalmente, a comparação nesse extrato e período conclui-se que as atividades administrativas não interferem negativamente em outras atividades, sequer na produção científica dos docentes.

\section{REFERÊNCIAS}

BARBOSA, L. Meritocracia à brasileira: o que é desempenho no Brasil? Revista do Serviço Público, Brasília, a. 47. v. 120, n. 3, set-dez 1996. Disponível em: $<$ http://www.bresserpereira.org.br/Documents/MARE/TerceirosPapers/96-Barbosa,L\%C3\%ADvia47(3).pdf>. Acesso em: 12 jan. 2011.

BARBOSA, L. Igualdade e meritocracia: a ética do desempenho nas sociedades modernas. 4. ed. Rio de Janeiro: Fundação Getúlio Vargas, 2003.

BARDIN, L. Análise de conteúdo. Lisboa: Edições 70, 2008.

COORDENAÇÃO DE APERFEIÇOAMENTO DE PESSOAL DE NÍVEL SUPERIOR. DIRETORIA DE AVALIAÇÃO. Documento de área 2009. Brasília, 2009. Disponível em: $<$ http://qualis.capes.gov.br/arquivos/avaliacao/Webqualis /criterios2007_2009/Criterios_Qualis_2008_03.pdf>. Acesso em: 12 jan. 2011.

Disponível

Relatório de Avaliação 2007-2009: trienal 2010. Brasília, 2011. content/uploads/2011/01/ASTRONOMIA-E-FÍSICA-RELATÓRIO-DE-

AVALIAÇÃO-FINAL-jan11.pdf > . Acesso em: 12 jan. 2011.

CORREIA, A. E. G. C. A influência exercida pelo sistema de avaliação da Capes na produção científica dos Programas de Pós-Graduação em Física. 2012. 215f. Tese - (Doutorado) Universidade Federal de Minas Gerais, Escola de Ciência da Informação. 2012.

REINACH, F. Darwin e a prática da 'Salami Science'. O Estado de S. Paulo, São Paulo, 23 de abr. 2013. Disponível em: <http://www.estadao.com.br/noticias /impresso,darwin-e-a-pratica-dasalami-science-,1026037,0.htm>. Acesso em: 2 maio 2013.

ROSA, A. R. "Nós e os índices" - um outro olhar sobre a pressão institucional por publicação. Rev. Adm. Empres., São Paulo, v. 48, n. 4, Oct./Dec. 2008.

Disponível em: <http://www.scielo.br/scielo.php?pid=S0034-75902008000400010 \&script=sci_arttext>. Acesso em: 17 nov. 2009. 
UNIVERSIDADE FEDERAL DE PERNAMBUCO. Conselho Universitário. Resolução no 04/2008. Boletim Oficial, Recife, v. 43, nesp. 80, p. 5-17, dez. 2008.

<http://www.

Manual da Pós-Graduação. Recife, 2011. Disponível em: foto3.pdf $>$. Acesso em: 21 out. 2011.

UNIVERSIDADE FEDERAL DO RIO DE JANEIRO. Instituto de Física. Regulamento dos Cursos de Pós-Graduação Instituto de Física da UFRJ. Disponível em: <http://omnis.if.ufrj.br/ pos/pdf/regulamento_2007_final_color.pdf>. Acesso em: 27 ago. 2009.

UNIVERSIDADE FEDERAL DE MINAS GERAIS. Instituto de ciências Exatas. Programa de Pós-Graduação em Física. Regulamento do Programa de PósGraduação em Física. 2010. Disponível em: <http://www.fisica.ufmg.br/posgrad/>. Acesso em: 27 ago. 2009. 